\title{
Alcohol and Risky Sexual Behavior among Heavy Drinking College Students
}

\author{
Lori A. J. Scott-Sheldon, Michael P. Carey, and Kate B. Carey \\ Center for Health and Behavior, Syracuse University
}

\begin{abstract}
Multiple event-level methodology was used to examine the relation between risky sexual behavior and alcohol use among sexually active, heavy drinking college students $(N=221)$. Using a structured timeline followback interview, participants reported their sexual, alcohol, and drug use behaviors over a 3-month period. Over 2,700 vaginal or anal sexual events were reported from 177 participants. Overall, condom use was not associated with heavy or non-heavy alcohol consumption among those reporting both sexual events concurrent with heavy drinking and when no alcohol was consumed. Results from multilevel regression analyses revealed a more complex pattern. Among women, but not men, less condom use was associated with steady vs. casual sexual partners, but partner type interacted with alcohol consumption such that less condom use occurred when heavy drinking preceded sex with steady partners. At the event-level, alcohol consumption among heavy drinking college students leads to risky sexual behavior but the relation differs by gender and partner type.
\end{abstract}

\section{Keywords}

condom use; alcohol use; HIV risk behavior; sexual behavior; event-level analysis

\section{INTRODUCTION}

Despite public health efforts to educate individuals about sexual risk behavior and provide solutions to reduce or avoid sexually transmitted diseases (STDs), young people continue to contract HIV and/or STDs at an alarming rate. Rates of HIV transmission continue to rise among young adults, ages 15 to 24, who accounted for approximately $14 \%$ of all new HIV cases in the U.S during 2005 (Centers for Disease Control and Prevention [CDC], 2006). The majority of these infections occur through male-to-male transmission (50\%) and heterosexual contact (36\%) (CDC, 2006). Furthermore, approximately half of all new STDs in the U.S. occur among young adults between the ages of 18 and 24 (Weinstock et al., 2004). Thus, evaluating risk behaviors of young adults and promoting risk reduction methods are critical in the prevention and/or reduction of the spread of HIV and other STDs.

Surveys of college campuses have found that at least $70 \%$ of young adults are sexually active (American College Health Association [ACHA], 2007; Siegel et al., 1999; Wiley et al., 1996). For sexually active individuals, correct and consistent condom use has proven to be an effective method of disease and pregnancy prevention (CDC, 2003; Niccolai et al., 2005). Yet, nearly half of young adults report that they did not use a condom the last time they had sex (ACHA, 2007), and many use condoms inconsistently (Seidman and Reider, 1994). In attempt to reduce the incidence of STDs among sexually active young adults, researchers have sought

Contact Information: Lori A. J. Scott-Sheldon, PhD, Center for Health and Behavior, Syracuse University, 430 Huntington Hall, Syracuse, NY 13244-2340, 1ajss@ syr.edu, Telephone: 315-443-9942, Facsimile: 315-443-4123. 
to identify factors that may influence condom use. One factor that has received much attention and study is the association of risky sexual behavior and alcohol use.

Despite popular belief that people engage in riskier sexual behavior after drinking alcohol, one prominent theory suggests the process may be more complex (Cooper, 2006). Cue salience models (Pernanen, 1976; Steele and Josephs, 1990; Taylor and Leonard, 1983) suggests that alcohol intoxication restricts cognitive capacity such that, when intoxicated, people are less able to attend to, or process, multiple situational cues; instead, intoxicated persons focus solely on the most salient cues. In a sexual situation, for example, the most salient cues are likely to involve sexual pleasure and arousal; when individuals are under the influence of alcohol, more subtle cues to sexual risk, such as a partner's HIV-status, may not be considered. Therefore, the salient cues of sexual pleasure and arousal may circumvent the distal cues to use condoms. Findings from some laboratory studies support this model (e.g., Gordon et al., 1997; MacDonald et al., 1998; MacDonald et al., 2000). For example, MacDonald and colleagues (2000) show that when intoxicated, sexually aroused participants intended to have more unprotected sex than when they were not intoxicated. Evidence of the relation between risky sexual behavior and alcohol use examining actual behavior, however, has been mixed (see Cooper 2002; Leigh and Stall, 1993 for reviews).

Researchers have suggested that inconsistent findings are related to the methods used to assess the link between risky sexual behavior and alcohol use (Cooper, 2002, 2006; Leigh and Stall, 1993; Weinhardt and Carey, 2000). In global association studies, participants report the number of times they engaged in unprotected sex and the overall frequency of their alcohol use during a specified reporting period (e.g., past 3 months); these studies tend to find positive relations between sexual risk behavior and alcohol use. For example, Wechsler and colleagues (1995) found that heavy drinking college students, compared to non-heavy drinking students, were nearly three times as likely to have had two or more sexual partners in the past month. In these studies, it is unclear whether participants engage in risky sexual behavior because they are drinking or as a result of some "third factor" such as the social environment that facilitates both behaviors.

In contrast, situational association studies typically look for associations between participants' (a) risky sexual behavior (frequency or dichotomous measure of engaging in risky sexual behavior) and (b) use of alcohol during sex (frequency or dichotomous measure of ever having sex concurrent with drinking). Consistent with the general findings from the global association studies, situational association studies find a positive relation between risky sexual behavior and alcohol use. This method provides more specific information than global association studies however, Leigh and Stall (1993) point out two limitations: (a) the relation between risky sexual behavior and alcohol use with sex may simply reflect the relation between total amount of sex and total amount of risky behavior and (b) the co-occurrence of risky sexual behavior and alcohol use is unclear (cf. Weinhardt and Carey, 2000).

Unlike global and situational association studies, event-level studies examine the co-occurrence of risky sex and alcohol use. A meta-analysis of 13 event-level studies examining discrete sexual events found a relation between risky sexual behaviors and alcohol use for first sexual experience but not for recent sexual experiences or recent sex with new partners (Leigh, 2002). Single event-level studies examining a single event represent an improvement over global and situational studies however, multiple-event studies provide even richer data (i.e., provide a more representative sample of an individual's sexual behavior over time). Analysis of multiple event-level data also allows for participants to serve as their own controls; making comparisons for each participants' risky sexual behavior concurrent with alcohol or when not drinking, while controlling for individual differences (Weinhardt et al., 2001). Despite the 
advantages of multiple event-level data, few studies have used this methodology (for reviews, see Cooper, 2002; Weinhardt and Carey, 2000).

In the current study, we use multiple event-level methodology to examine the relation between risky sexual behavior and alcohol use among heavy drinking college students. The timeline followback method (TLFB; Sobell and Sobell, 1996) was used to obtain multiple event-level data while minimizing the potential reactivity of daily reports (which may induce behavioral changes due to the daily reminder of participants' behavior; Weinhardt et al., 2001). Given (a) the high rates of alcohol consumption and heavy episodic (binge) drinking among college students, compared with their non-college/part-time college peers (Substance Abuse and Mental Health Services Administration [SAMHSA], 2006), (b) the low rates of condom use in this population (ACHA, 2007; Seidman and Reider, 1994), and (c) the association of alcohol use and risky sexual behavior (e.g., multiple sexual partners; Cooper, 2002), examining multiple sexual events in a high-risk sample of college students (i.e., sexually active, heavy drinkers) can elucidate the relation between sexual behavior and alcohol use. Moreover, such research can explore individual (e.g., gender) and situational (e.g., partner type, the use of another form of birth control) factors related to risky sexual behavior. Gender may be an important moderator of risky sexual behavior and alcohol consumption (c.f., Cooper \& Orcutt, 2000; Neal \& Fromme, 2007), however, results from meta-analytic and literature reviews (examining single event-level studies) have found an inconsistent relation between risky sexual behavior and alcohol consumption with respect to gender (see Cooper, 2002; Leigh, 2002; Weinhardt and Carey, 2000). Because men consume more alcohol, have direct control over condom use, and avoidance of condom use is seen as more masculine (Campbell, 1995; Capraro, 2000; DeBro, Campbell, and Peplau, 1994; O'Malley and Johnston, 2002; Pearson, 2006), the relation between alcohol consumption and condom use may be more pronounced for men rather than women. Several studies have suggested that partner type (i.e., casual vs. steady) influences the degree to which alcohol consumption is related to risky sex (e.g., Brown and Vanable, 2007; LaBrie et al., 2005; Testa and Collins, 1997). Event-level studies among college students have shown both an increase (e.g., Brown and Vanable, 2007) and decrease (e.g., Leigh et al., 2008) in the probability of unprotected vaginal sex concurrent with alcohol consumption with casual sexual partners. Research also shows a decrease in condom use among individuals using another form of birth control (Dekin, 1996; Leigh et al., 2008; Middleman et al., 1997). Examining the relation between sexual behavior and alcohol use, including factors known to be related to risky sexual behavior, can guide intervention development to reduce or avoid HIV and/or other STDs among young adults.

We extend limited previous research in this population by examining alcohol use and sexual behavior patterns among women as well as men, and distinguishing between sexual events following heavy episodic (binge) alcohol use and non-heavy (binge) alcohol use (cf. LaBrie et al., 2005; Leigh et al., 2008). Using a multiple event methodology, and guided by cue salience models (Pernanen, 1976; Steele and Josephs, 1990; Taylor and Leonard, 1983) as well as extant research, we expected condom use would be less likely during vaginal or anal sex after alcohol consumption occurred compared to when alcohol was not consumed; because the salient cues of sexual arousal may reinforce men's desire to exert their masculinity and discount requests for condom use, men would be less likely to use condoms when drinking compared with women; condoms would be used more frequently with casual rather than steady partners; and would be reduced when another form of birth control (e.g., oral contraceptives) was used because condom use diminishes as the strength of a relationship increases (Cooper and Orcutt, 2000; Macaluso et al., 2000); and gender and partner type would interact such that men would use condoms less with casual, but not steady, sexual partners after heavy drinking.. 
METHOD

Participants

Participants were 221 undergraduates (67\% female, 87\% White, $M$ age $=19$ years, 55\% freshman, 21\% Greek members/pledges) attending Syracuse University. Inclusion criteria included reporting (a) $\geq 1$ episode of heavy episodic drinking (i.e., five drinks on a single occasion for men, four for women) episodes in the last month (Wechsler et al., 1994); (b) sexual activity during the past 90 days (defined as having any vaginal, anal, or oral sex); and (c) age of 18 to 25 . The study was approved by Syracuse University Institutional Review Board and written informed consent was obtained from all participants.

\section{Procedures}

Participants participated in a larger study examining brief motivational interventions for heavy college drinkers (Carey et al., 2006). Introductory psychology students who volunteered to participate in the study in exchange for partial course credit were administered baseline questionnaires in groups. Students providing contact information (i.e., indicating they were interested in participating in the larger study) were telephoned and given further details. Interested students met with a research assistant (RA) in a private office and provided written consent. A subset of consenting participants were randomly assigned to complete the TLFB interview. (The alcohol intervention was not initiated until the following week.) Of the 262 participants who completed the TLFB interview, $84 \%(n=221)$ were sexually active and were included in the analyses.

\section{Measures}

A modified and validated version of TLFB interview was administered by trained RAs using standard procedures (Carey et al., 2001; Sobell and Sobell, 1996). A calendar, marked with university holidays and campus events, was used to aid participants' recall of their behaviors. RAs sequentially assessed participants' alcohol use, drug use, and sexual behavior starting with the current week and working backwards for a total of 12 weeks. In the sexual behavior phase of the assessment, participants first identified the number of sexual partners they had in the last 12 weeks; they reported partner(s) initials, gender, whether or not they were in a committed relationship (defined as both partners having an understanding that they will not have sex with other people), and the length of the relationship. Partner type was coded as steady if the participant reported a committed relationship for the last two months and casual if participant reported a non-committed relationship (i.e., has sex with occasionally and both partners having an understanding that they will have sex with other people). Next, for each sexual event, participants reported the number and type of sex (vaginal, anal, or oral), partner initials, whether condoms and/or other birth control (e.g., oral contraceptives) were used, and if they were under the influence of alcohol and/or drugs. Participants were given definitions of standard drinks and sexual terms (e.g., vaginal, anal, or oral sex). TLFB interviews were typically completed in 30 minutes.

\section{Data Management and Analysis}

The TLFB data were entered independently by two RAs, checked for accuracy, and corrected. Data abstraction was restricted to vaginal or anal sexual events only given the relatively lower risk of HIV and other STDs associated with oral sex (Campo et al., 2006). For all of the analyses, results are based on variables that combine vaginal or anal sex; oral sex is not included. Thus, when we use the term "sex," we are referring to vaginal or anal sex. Because we focused on alcohol use, sexual events concurrent with drug use were excluded from the analyses. 
We used two types of analyses to test our predictions: (a) within-subjects $t$-tests and (b) multilevel regression modeling. To directly evaluate the within-person effects of alcohol use on sexual behavior, we conducted within-subjects $t$-tests. These tests compared participants' condom use with concurrent alcohol use (i.e., non-heavy alcohol consumption, heavy drinking) compared with their condom use when no alcohol was consumed. The proportion of protected sexual events concurrent with non-heavy alcohol consumption, heavy drinking, or when no alcohol consumption occurred was calculated using the following formula: number of protected sex events divided by the sum of the number of unprotected and protected sex events. These three variables (protected sex with concurrent alcohol consumption, heavy drinking, or nonheavy alcohol consumption) were also calculated by gender and partner type (steady, casual). Because we assumed that alcohol consumption would undermine condom use (i.e., a directional hypothesis), we used one-tailed significance tests.

Due to the hierarchical structure of the data (i.e., sexual events nested within participants), we used the generalized linear mixed model (GLIMMIX) procedure of SAS (with a binomial distribution and logit link function) to further examine the relation between condom use and alcohol consumption. Specifically, the probability of condom use (yes, no) was predicted from alcohol consumption concurrent with sex (heavy drinking and non-heavy drinking events; yes, no), partner type (casual, steady), and use of other birth control (yes, no) for the 175 participants reporting vaginal or anal sex events (two participants were dropped from analyses due to extreme number of sexual events reported). Generalized linear mixed models (or randomeffects regression models) extend generalized linear models by including random effects in the predictors thus accounting for the correlated nature of the data (Hedeker and Mermelstein, 2007; Schabenberger 2005; Zhou, Perkins, and Hui, 1999). Among the advantages afforded by these models, (a) there is no assumption that participants are measured at the same time or the same number of time points, and (b) the models can estimate participant-specific change (Hedeker and Mermelstiein, 2007).

\section{RESULTS}

\section{Characteristics of the Sample}

In the past 3 months, a total of 5,152 sexual events were reported (2,722 vaginal, 31 anal, and 2,399 oral events). Overall, participants reported an average of $23.29(S D=29.03)$ sexual events $(M d n=13.00$, range $=1-175$ events). Of the 221 (67\% female) sexually active participants, $177(80 \%$; 68\% female) reported having vaginal or anal sex. The number of vaginal sexual events ranged from 1 to $89(M=15.47, S D=16.45, n=177)$ and anal events ranged from 1 to $23(M=3.88, S D=7.74, n=8)$. A total of 663 vaginal or anal sexual events concurrent with alcohol and/or drugs were reported by 124 (70\%) participants. Of these events, 526 events occurred with alcohol only, 80 with alcohol and drugs, and 57 with drugs only. Marijuana was the most frequently used drug concurrent with sex (90\% of combined alcohol and drug events and $82 \%$ of drug-only events). ${ }^{1}$ Condoms were used in $1,517(55 \%)$ of the vaginal and anal sexual events. Steady sexual partners accounted for 2,204 (80\%) vaginal and anal events whereas $549(20 \%)$ sexual events were with casual partners. Table 1 reports a summary of participants' behavioral characteristics.

\section{Event-Level Analyses}

Direct effect of alcohol on condom use-Condom use was examined among participants reporting either concurrent heavy drinking (i.e., $\geq 5$ drinks for men, $\geq 4$ drinks for women; Wechsler et al., 1995) or non-heavy drinking, and no alcohol consumption events.

\footnotetext{
${ }^{1}$ For the final sample $(N=175)$, 534 sexual events concurrent with alcohol consumption were reported (57 events concurrent with druguse only were excluded). Drugs were used in $76(14 \%)$ of those events, most frequently (89\%) marijuana use.
} 
Table 2 reports the proportion of condom use concurrent with heavy alcohol consumption, non-heavy alcohol consumption, and when no alcohol consumption occurred. Contrary to our hypotheses, heavy and non-heavy alcohol consumption was not associated with rates of condom use among those reporting both sexual events concurrent with heavy drinking and when no alcohol was consumed. Differences in unprotected sex by gender and partner type were also examined: heavy alcohol consumption was marginally associated with less condom use among men $(p=.07)$ and significantly associated with steady sexual partners $(p<.01)$.

Predicting the probability of condom use-Multilevel regression modeling was used to predict the probability of condom use (yes, no) from heavy or non-heavy alcohol consumption concurrent with sex (yes, no) for the 175 participants reporting vaginal or anal sex events. As a preliminary analysis we fit simple models of condom use followed by two models that included partner type (steady, casual) and the use of another form of birth control (yes, no) as event-level variables. Consistent with our direct test of alcohol consumption on condom use, the probability of condom use was not associated with heavy drinking concurrent with sex (Odds Ratio $[\mathrm{OR}]=0.75,95 \%$ confidence interval $[\mathrm{CI}]=0.48,1.17$; results not tabled) or non-heavy alcohol consumption $(\mathrm{OR}=0.89,95 \% \mathrm{CI}=0.32,2.44$; results not tabled).

Table 3 reports the results of the analyses with the event-level variables by men and women. In these analyses, we include an interaction term (computed from the alcohol consumption and partner type dichotomous variables) that can be interpreted as showing the interaction of sex concurrent with heavy drinking (or non-heavy drinking) with steady sex partners For men, the odds of condom use was not related to alcohol consumption (heavy or non-heavy drinking). In both models, the odds of condom use were reduced when men's partners used another form of birth control. Partner type was not associated with condom use among men.

For women, condom use was reduced when a woman reported steady vs. casual sexual partners and decreased with the use of another form of birth control. The relationships between type of drinking event and condom use were more complex. By itself, type of drinking event did not influence condom use; rather, heavy alcohol consumption interacted with partner type. Thus, contrary to our hypotheses, during heavy episodic drinking events, women were less likely to use a condom with a steady partner.

\section{DISCUSSION}

The current study used multiple-event level methodology to examine the relation between risky sexual behavior and concurrent alcohol use among heavy drinking college men and women over a three-month period. Results from this study provide evidence of a relation between unprotected vaginal and anal sex (i.e., less condom use) concurrent with heavy alcohol consumption but this relation varied by gender and partner type (steady vs. casual). Withinsubjects analyses, restricted to those who reported both heavy alcohol consumption concurrent with sex and sex when no alcohol consumption occurred, revealed an association between less condom use and heavy alcohol consumption with steady but not casual sexual partners, contrary to our hypotheses. Our multilevel regression models showed a more complex pattern. Consistent with the within-subjects analyses, condom use was unrelated to alcohol consumption for both men and women. Among women, but not men, less condom use was associated with steady vs. casual sexual partners, but partner type interacted with alcohol consumption such that less condom use occurred when heavy drinking preceded sex with steady partners. Accordingly, our study reveals gender-linked patterns with distinct prevention implications. Overall, these results elucidate the need to address the following two aspects associated with risky sexual behavior. 
First, failure to use condoms concurrent with alcohol consumption in steady sexual relationships suggests that the risk of HIV and/or STDs may be higher for young adults with steady rather than casual sexual partners. Steady relationships are often perceived to be inherently safe whereas casual relationships are perceived to be risky (Hammer et al., 1996; Misovich et al., 1997). Because condoms are typically used for pregnancy (rather than disease) prevention (Cooper et al., 1999), condoms are often replaced with the use of oral contraceptives as a relationship develops (e.g., Cooper and Orcutt, 2000; Lansky et al., 1998; Macaluso et al., 2000). Thus, established sexual scripts with steady partners preclude safer sex discussions and/ or negotiations. Alcohol consumption may further restrict discussion of safer sex practices among steady partners as couples are likely to rely on these implicit sexual scripts when the opportunity for sex arises (c.f., Pernanen, 1976; Steele and Josephs, 1990; Taylor and Leonard, 1983). Among young adults, however, those steady relationships are typically characterized as a series of sequential short-term ("serial") monogamous relationships (e.g., Hammer et al., 1996; Moore and Rosenthal, 1991). Reliance on established sexual scripts that typically include pregnancy- but exclude disease-prevention methods in serially monogamous relationships exacerbates the risk of STD infection. Indeed, mathematical models have shown serial monogamous or concurrent relationships accelerate the spread of HIV and/or STDs (e.g., Kretzschmar and Morris, 1996).

Second, our finding that women have more unprotected sex with a steady partner after heavy drinking suggests that gender-based power imbalance (see Amaro, 1995; Wingood and DiClemente, 2000) may inhibit women's ability to negotiate safer sex. Because men have direct control over male condom use, women must rely on the cooperation of their male partners to use male condoms (Pearson, 2006). Relationship power inequality may thwart women-initiated disease-prevention (i.e., female condom use) as well as discussion and/or negotiation with a sexual partner (e.g., Pulerwitz et al., 2002; Wingood and DiClemente, 1998). Not only does lack of relationship power impact a woman's ability to negotiate safer sex, lack of power may also inhibit her ability to refuse sex in coercive situations (e.g., Muehlenhard and Linton, 1987; Testa and Livingston, 2000). Alcohol consumption may further inhibit a women's ability to refuse sex (e.g., Pumphrey-Gordon and Gross, 2007) and may lead to misperceptions in women's intentions for sex. Indeed, numerous studies have documented the relation between alcohol consumption and sexual coercion among college students (for reviews, see Abbey, 2002; Adams-Curtis and Forbes, 2004). Once a sexual script has been established in these unequal power relationships, alcohol use is again likely to lead to increased sexual risk. For women, the combination of gender-based power imbalance and alcohol consumption may be particularly detrimental as women's risk of contracting HIV and/or STDs through heterosexual contact is eight times higher than that of men (Padian et al., 1997).

Risky sexual behavior associated with serial monogamy and relationship inequality suggests a need for further intervention development among steady relationship partners. Too often, sexual risk-reduction interventions are individually-based rather than partner-specific. These interventions may address interpersonal communication and/or negotiation needs but in the absence of the participants' steady partner. Partner-specific interventions would not only provide relationship building opportunities (which may lessen relationship inequality) but would also afford discussions of the importance of condom use in steady relationships, condom skills training that focuses on eroticizing safer sex, and the role of alcohol in safer sex decision making. Some dyadic programs have been developed (e.g., Wu et al., 2005) but they have not, to our knowledge, been implemented with college student couples. Addressing prevention needs among young adults in serially monogamous relationships is imperative in reducing the spread of HIV and/or STDs.

Several factors are important in interpreting these findings. First, our sample of sexually-active heavy drinking college students attending a university in upstate New York is a limited sample 
that may not be representative of the overall population of heavy-drinking individuals. Still, examining the relation between risky sexual behavior and alcohol use among high-risk college students is valuable given the high rates of alcohol consumption, lack of condom use, and association of alcohol use and risky sexual behavior among college students. Second, the data were gathered from retrospective self-reports which may increase recall errors (e.g., recent and/or salient events recalled more accurately than earlier and/or indistinctive events). To minimize these memory errors we used an assessment tool that included techniques to aid participant recall (Carey et al., 2001). Additionally, previous research has demonstrated the test-retest reliability of the TLFB interview for sexual behavior (Weinhardt et al., 1998). Third, we did not assess other individual characteristics (e.g., coping style, sensation seeking) that may account for the association between risky sexual behavior and alcohol use. Nonetheless, by using a within-subjects design, we reduced error variance associated with individual differences given that participants served as their own controls.

\section{CONCLUSION}

This research supported the popular belief that unprotected sex is associated with alcohol use at the event-level but this relation differs by gender and partner type. The present research suggests that interventions among sexually-active heavy-drinking college students should focus on the risk of STD transmission in steady relationships, which tend to be serially monogamous in this population (see Hammer et al., 1996). Sexual risk-reduction interventions often focus on and find the most change by addressing casual rather than steady relationships (e.g., Keller and Brown, 2002; Sanderson, 1999). Failure to use condoms, especially among women, in steady relationships may put young people at increased risk of HIV infection. Future intervention development should focus on partner-specific interventions to address the lack of condom use and perceived safety of steady sexual relationships.

\section{Acknowledgments}

This research was supported by grant R01-AA012518 from the National Institutes of Health. We thank the SURE Project team for help with data collection, Jamie R. Bolles for assistance with data entry, and Alecia M. Santuzzi, $\mathrm{PhD}$, for her assistance with analyses.

\section{References}

Abbey A. Alcohol-related sexual assault: A common problem among college students. Journal of Studies on Alcohol 2002;14:118-128.

Adams-Curtis LE, Forbes GB. College women's experiences of sexual coercion: A review of cultural, perpetrator, victim, and situational variables. Trauma, Violence, \& Abuse 2004;5:91-122.

Amaro H. Love, sex, and power: Considering women's realities in HIV prevention. American Psychologist 1995;50:437-447. [PubMed: 7598292]

American College Health Association. American College Health Association national college health assessment: Reference group executive summary. 2007. Retrieved July 19, 2007 from http://www.acha-ncha.org/docs/ACHA-

NCHA_Reference_Group_ExecutiveSummary_Fall2006.pdf

Brown JL, Vanable PA. Alcohol use, partner type, and risky sexual behavior among college students: Findings from an event-level study. Addictive Behaviors 2007;32:2940-2952. [PubMed: 17611038]

Campbell CA. Male gender roles and sexuality: Implications for women's AIDS risk and prevention. Social Science \& Medicine 1995;41:197-210. [PubMed: 7667682]

Campo J, Perea MA, del Romero J, Cano J, Hernando V, Bascones A. Oral transmission of HIV, reality or fiction? An update. Oral Diseases 2006;12:219-228. [PubMed: 16700731]

Capraro RL. Why college men drink: Alcohol, adventure, and the paradox of masculinity. Journal of American College Health 2000;48:307-315. [PubMed: 10863874] 
Carey KB, Carey MP, Maisto SA, Henson JM. Brief motivational interventions for heavy college drinkers: A randomized controlled trial. Journal of Consulting and Clinical Psychology 2006;74:943954. [PubMed: 17032098]

Carey MP, Carey KB, Maisto SA, Gordon CM, Weinhardt LS. Assessing sexual risk behaviour with the Timeline Followback (TLFB) approach: Continued development and psychometric evaluation and psychiatric outpatients. International Journal of STD \& AIDS 2001;12:365-375. [PubMed: 11368817]

Centers for Disease Control and Prevention. Fact sheet for public health personnel: Male latex condoms and sexually transmitted diseases. 2003. Retrieved July 20, 2007 from http://www.cdc.gov/nchstp/od/condoms.pdf

Centers for Disease Control and Prevention. HIV/AIDS Surveillance Report, 2005. Vol. 17. Atlanta: U.S. Department of Health and Human Services; 2006. [inclusive page numbers]

Cooper ML. Alcohol use and risky sexual behavior among college students and youth: Evaluating the evidence. Journal of Studies on Alcohol 2002;14 (Suppl):101-117.

Cooper ML. Does drinking promote risky sexual behavior? A complex answer to a simple question. Current Directions in Psychological Science 2006;15:19-23.

Cooper ML, Agocha VB, Powers AM. Motivations for condom use: Do pregnancy prevention goals undermine disease prevention among heterosexual young adults? Health Psychology 1999;18:464474. [PubMed: 10519462]

Cooper ML, Orcutt HK. Alcohol use, condom use and partner type among heterosexual adolescents and young adults. Journal of Studies on Alcohol 2000;61:413-419. [PubMed: 10807212]

DeBro SC, Campbell SM, Peplau LA. Influencing a partner to use a condom: A college student perspective. Psychology of Women Quarterly 1994;18:165-182. [PubMed: 12287707]

Dekin B. Gender differences in HIV-related self-reported knowledge, attitudes, and behaviors among college students. American Journal of Preventive Medicine 1996;12:61-66. [PubMed: 8874706]

Gordon CM, Carey MP, Carey KB. Effects of a drinking event on behavioral skills and condom attitudes in men: Implications for HIV risk from a controlled experiment. Health Psychology 1997;16:490 495. [PubMed: 9302547]

Hammer JC, Fisher JD, Fitzgerald P, Fisher WA. When two heads aren't better than one: AIDS risk behavior in college-age couples. Journal of Applied Social Psychology 1996;26:375-397.

Hedeker, D.; Mermelstein, RJ. Mixed-effects regression models with heterogeneous variance: Analyzing ecological momentary assessment (EMA) data of smoking. In: Little, TD.; Bovaird, JA.; Card, NA., editors. Modeling Contextual Effects in Longitudinal Studies. Erlbaum; Mahwah, NJ: 2007.

Keller SN, Brown JD. Media interventions to promote responsible sexual behavior. Journal of Sex Research 2002;39:67-72. [PubMed: 12476260]

Kretzschmar M, Morris M. Measures of concurrency in networks and the spread of infectious disease. Mathematical Biosciences 1996;133:165-195. [PubMed: 8718707]

LaBrie J, Earleywine M, Schiffman J, Pedersen E, Marriot C. Effects of alcohol, expectancies, and partner type on condom use in college males: Event-level analyses. The Journal of Sex Research 2005;42:259-266.

Lansky A, Thomas JC, Earp JA. Partner-specific sexual behaviors among persons with both main and other partners. Family Planning Perspectives 1998;30:93-96. [PubMed: 9561875]

Leigh BC. Alcohol and condom use: A meta-analysis of event-level studies. Sexually Transmitted Diseases 2002;29:476-482. [PubMed: 12172533]

Leigh BC, Stall R. Substance use and risky sexual behavior for exposure to HIV: Issues in methodology, interpretation, and prevention. American Psychologist 1993;48:1035-1045. [PubMed: 8256876]

Leigh BC, Vanslyke JG, Hoppe MJ, Rainey DT, Morrison DM, Gillmore MR. Drinking and condom use: Results from an event-based daily diary. AIDS and Behavior 2008;12:104-112. [PubMed: 17333311]

Macaluso M, Demand MJ, Artz LM, Hook EW III. Partner type and condom use. AIDS 2000;14:537546. [PubMed: 10780716]

Misovich SJ, Fisher JD, Fisher WD. Close relationships and elevated HIV risk behavior: Evidence and possible underlying psychological processes. Review of General Psychology 1997;1:72-107. 
MacDonald TK, MacDonald G, Zanna MP, Fong GT. Alcohol, sexual arousal, and intentions to use condoms in young men: Applying alcohol myopia theory to risky sexual behavior. Health Psychology 2000;19:290-298. [PubMed: 10868774]

MacDonald, TK.; Zanna, MP.; Fong, GT. Alcohol and intentions to engage in risky health-related behaviors: Experimental evidence for a causal relationship. In: Adair, JG.; Belanger, D.; Dion, K., editors. Advances in Psychological Science: Vol. 1: Social, Personal and Cultural aspects. East Sussex, United Kingdom: Psychology Press; 1998. p. 407-428.

Middleman AB, Robertson LM, DuRant RH, Chiou V, Emans SJ. Use of hormonal methods of birth control among sexually active adolescent girls. Journal of Pediatric and Adolescent Gynecology 1997;10:193-198. [PubMed: 9391901]

Moore S, Rosenthal D. The social context of adolescent sexuality: Safer sex implications. Journal of Adolescence 1991;15:415-435. [PubMed: 1487577]

Muehlenhard CL, Linton MA. Date rape and sexual aggression in dating situations: Incidence and risk factors. Journal of Counseling Psychology 1987;34:186-196.

Neal DJ, Fromme K. Event-level covariation of alcohol intoxication and behavioral risks during the first year of college. Journal of Consulting and Clinical Psychology 2007;75:294-306. [PubMed: 17469887]

Niccolai LM, Rowhani-Rahbar A, Jenkins H, Green S, Dunne DW. Condom effectiveness for prevention of Chlamydia trachomatis infection. Sexually Transmitted Infections 2005;81:323-325. [PubMed: 16061540]

O'Malley PM, Johnston LD. Epidemiology of alcohol and other drug use among American college students. Journal of Studies on Alcohol 2002;Suppl 14:23-39.

Padian NS, Schiboski SC, Glass SO, Vittinghoff E. Heterosexual transmission of human immunodeficiency virus (HIV) in northern California: Results from a ten-year study. American Journal of Epidemiology 1997;146:350-357. [PubMed: 9270414]

Pearson J. Personal control, self-efficacy in sexual negotiation, and contraceptive risk among adolescents: The role of gender. Sex Roles 2006;54:615-625.

Pernanen, K. Alcohol and crimes of violence. In: Kissin, B.; Begleiter, H., editors. The Biology of Alcoholism: Vol. 4. Social Aspects of Alcoholism. New York: Plenum Press; 1976. p. 351-444.

Pumphrey-Gordon JE, Gross AM. Alcohol consumption and females' recognition in response to date rape risk: The role of sex-related alcohol expectancies. Journal of Family Violence 2007;22:475485.

Pulerwitz J, Amaro H, DeJong W, Gortmaker SL, Rudd R. Relationship power, condom use and HIV risk among women in the USA. AIDS Care 2002;14:789-800. [PubMed: 12511212]

Sanderson CA. Role of relationship context in influencing college students' responsiveness to HIV prevention videos. Health Psychology 1999;18:295-300. [PubMed: 10357511]

Schabenberger, O. Introducing the GLIMMIX procedure for generalized linear mixed models. Paper presented at the 30th annual SAS Users Group International (SUGI) conference; Philadelphia, PA. 2005 Apr.

Seidman SN, Reider RO. A review of sexual behavior in the United States. American Journal of Psychiatry 1994;151:330-341. [PubMed: 7619092]

Siegel DM, Klein DI, Roghmann KJ. Sexual behavior, contraception, and risk among college students. Journal of Adolescent Health 1999;25:336-343. [PubMed: 10551664]

Sobell, LC.; Sobell, MB. Timeline followback user's guide. Toronto, Canada: Alcohol Research Foundation; 1996.

Steele CM, Josephs RA. Alcohol myopia: Its prized and dangerous effects. American Psychologist 1990;43:921-933. [PubMed: 2221564]

Substance Abuse and Mental Health Services Administration. Results from the 2005 national survey on drug use and health: National findings (Office of Applied Studies, NSDUH Series H-30, DHHS Pub. No. SMA 06-4194). Rockville, MD: author; 2006.

Taylor, SP.; Leonard, KE. Alcohol and human aggression. In: Geen, RG.; Donnerstein, EI., editors. Aggression: Theoretical and Empirical Reviews. New York: Academic Press; 1983. p. 77-102.

Testa M, Collins RL. Alcohol and risky sexual behavior: Event-based analyses among a sample of highrisk women. Psychology of Addictive Behaviors 1997;11:190-201. 
Testa M, Livingston JA. Alcohol and sexual aggression: Reciprocal relationships over time in a sample of high-risk women. Journal of Interpersonal Violence 2000;15:413-427.

Weinhardt LS, Carey MP. Does alcohol lead to sexual risk behavior? Findings from event-level research. Annual Review of Sex Research 2000;11:125-157.

Weinhardt LS, Carey MP, Carey KB, Maisto SA, Gordon CM. The relation of alcohol use to HIV-risk sexual behavior among adults with a severe and persistent mental illness. Journal of Consulting and Clinical Psychology 2001;69:77-84. [PubMed: 11302280]

Weinhardt LS, Carey MP, Maisto SA, Carey KB, Cohen MM, Wickramasinghe SM. Reliability of the timeline follow-back sexual behavior interview. Annals of Behavioral Medicine 1998;20:25-30. [PubMed: 9755348]

Weinstock H, Berman S, Cates W. Sexually transmitted diseases among American youth: Incidence and prevalence estimates, 2000. Perspectives on Sexual and Reproductive Health 2004;36:6-10. [PubMed: 14982671]

Wechsler H, Davenport A, Dowdall G, Moeykens B, Castillo S. Health and behavioral consequences of binge drinking in college. A national survey of students at 140 campuses. Journal of the American Medical Association 1994;272:1672-1677. [PubMed: 7966895]

Wechsler H, Dowdall GW, Davenport A, Castillo S. Correlates of college student binge drinking. American Journal of Public Health 1995;85:921-926. [PubMed: 7604914]

Wiley DC, James G, Jordan-Belver C, Furney S, Calsbeek F, Benjamin J, Kathcart T. Assessing the health behaviors of Texas college students. Journal of American College Health 1996;44:167-172. [PubMed: 8583041]

Wingood GM, DiClemente RJ. Application of the theory of gender and power to examine HIV-related exposures, risk factors, and effective interventions for women. Health Education and Behavior 2000;27:539-565. [PubMed: 11009126]

Wingood GM, DiClemente RJ. Partner influences and gender-related factors associated with noncondom use among young adult African American women. American Journal of Community Psychology 1998;26:29-51. [PubMed: 9574497]

Wu E, El-Bassel N, Witte SS, Gilbert L, Chang M, Morse P. Enrollment of minority women and their main sexual partners in an HIV/STI prevention trial. AIDS Education and Prevention 2005;17:4152. [PubMed: 15843109]

Zhou XH, Perkins AJ, Hui SL. Comparisons of software packages for generalized linear multilevel models. The American Statistician 1999;53:282-290. 
Table 1

Participants' Behavioral Characteristics

\begin{tabular}{lccc}
\hline Behavioral Characteristics & Overall $(\boldsymbol{N}=\mathbf{2 2 1})$ & Females $(\boldsymbol{n}=\mathbf{1 4 7})$ & Males $(\boldsymbol{n}=\mathbf{7 4})$ \\
\hline Sexual activity (past 3 months) & & & \\
$\quad$ Vaginal Sex & $80 \%$ & $82 \%$ & $73 \%$ \\
$\quad$ Anal Sex & $4 \%$ & $4 \%$ & $3 \%$ \\
$\quad$ Oral Sex & $87 \%$ & $83 \%$ & $95 \%$ \\
Sex partner type (past 3 months) & & & \\
Casual Only & $39 \%$ & $38 \%$ & $41 \%$ \\
Steady Only & $43 \%$ & $46 \%$ & $38 \%$ \\
Both Casual and Steady & $18 \%$ & $16 \%$ & $22 \%$ \\
$M \%$ condom use during vaginal or anal sex & $55 \%$ & $54 \%$ & $58 \%$ \\
Vaginal or anal sex events by partner type & & & \\
$\%$ events with steady & $80 \%$ & $79 \%$ & $81 \%$ \\
$\%$ events with casual & $20 \%$ & $21 \%$ & $19 \%$ \\
\hline
\end{tabular}




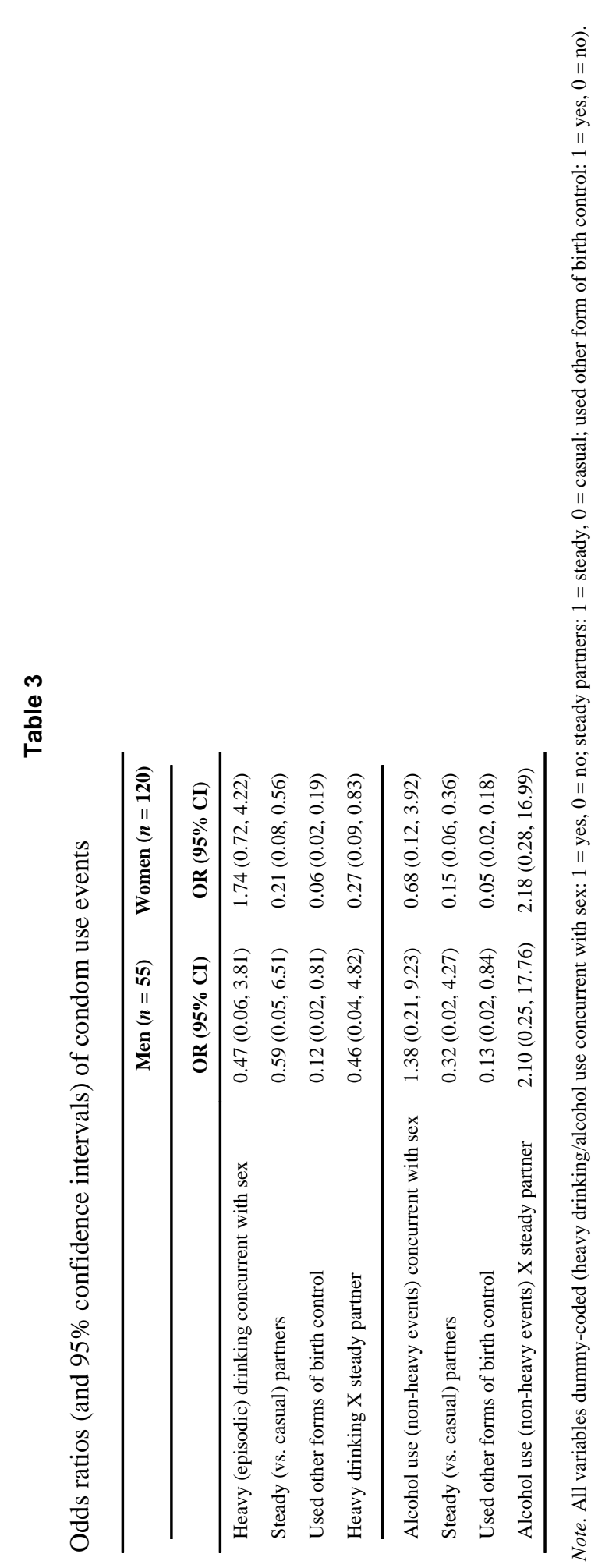

AIDS Behav. Author manuscript; available in PMC 2010 November 16. 